\title{
Impact of liposomal amphotericin B therapy on chronic pulmonary aspergillosis
}

DOI:

10.1016/j.jinf.2016.06.001

\section{Document Version}

Accepted author manuscript

Link to publication record in Manchester Research Explorer

\section{Citation for published version (APA):}

Newton, P. J., Harris, C., Morris, J., \& Denning, D. W. (2016). Impact of liposomal amphotericin B therapy on chronic pulmonary aspergillosis. The Journal of infection, 73(5), 485-495. https://doi.org/10.1016/j.jinf.2016.06.001

\section{Published in:}

The Journal of infection

\section{Citing this paper}

Please note that where the full-text provided on Manchester Research Explorer is the Author Accepted Manuscript or Proof version this may differ from the final Published version. If citing, it is advised that you check and use the publisher's definitive version.

\section{General rights}

Copyright and moral rights for the publications made accessible in the Research Explorer are retained by the authors and/or other copyright owners and it is a condition of accessing publications that users recognise and abide by the legal requirements associated with these rights.

\section{Takedown policy}

If you believe that this document breaches copyright please refer to the University of Manchester's Takedown Procedures [http://man.ac.uk/04Y6Bo] or contact uml.scholarlycommunications@manchester.ac.uk providing relevant details, so we can investigate your claim.

\section{OPEN ACCESS}


Journal of Infection - In press

Title:

Impact of liposomal amphotericin B therapy on chronic pulmonary aspergillosis Running title:

\section{Liposomal amphotericin B in CPA}

Pippa J. Newton ${ }^{1}$, Chris Harris ${ }^{1}$, Julie Morris ${ }^{2}$, David W. Denning ${ }^{1}$

${ }^{1}$ The National Aspergillosis Centre, University Hospital of South Manchester, The University of Manchester, Manchester Academic Health Science Centre, Manchester, UK

${ }^{2}$ Department of Medical Statistics, University Hospital of South Manchester, The University of Manchester, Manchester Academic Health Science Centre, Manchester, UK

Corresponding author: Dr Pippa Newton

ERC, $2^{\text {nd }}$ floor, Wythenshawe Hospital, Manchester M23 9LT, UK

Tel: +44 161291 5811/5818, Fax: +44 1612915806 (FAX),

Email: pippa.newton@uhsm.nhs.uk or pippanewton@nhs.net 


\section{Abstract}

Objectives: To assess the clinical response and renal toxicity observed in chronic pulmonary aspergillosis (CPA) patients receiving $\geq 1$ short-courses of liposomal amphotericin (LAmB) (AmBisome®) therapy.

Methods: A retrospective audit of clinical response and renal function was undertaken in 71 CPA patients (41 male) treated with LAmB at the National Aspergillosis Centre, including 20 patients receiving repeated treatment courses or long-term therapy $(n=5)$.

Results: Median age was 64 years (range 29 - 86 years). Treatment indications included respiratory symptoms $(\mathrm{N}=33 ; 46.5 \%)$, constitutional symptoms $(\mathrm{N}=2 ; 2.8 \%)$ or both $(\mathrm{N}=36$; 50.7\%). 48 patients (73.8\%) responded to their first LAmB course. Quality of life (QOL) improvements occurred in 37 (92.5\%) of 40 patients with sufficient data available. Response rates for repeated short-courses of LAmB were 76.6\%; QOL improvements were observed in $91.7 \%$ of treatment courses. All patients on long-term therapy demonstrated a response. 34 (50\%) and 17 (25\%) patients respectively developed an increased risk of acute kidney injury (AKI) or actual AKI with their first treatment; a significant reduction in geometric mean eGFR was observed and a similar pattern occurred following their second treatment course.

Conclusions: Whilst CPA is responsive to LAmB, caution should be exercised with repeated courses, if other treatments are available.

\section{Key words:}

Liposomal amphotericin B, chronic pulmonary aspergillosis, Aspergillus, acute kidney injury, quality of life

\section{Highlights:}

- Clinical response to the first LAmB course in CPA patients was $74 \%$

- Improvements in QOL in CPA patients after their first LAmB was 92\%

- $50 \%$ of CPA patients had an increased risk of AKI with their first LAmB course

- $25 \%$ of CPA patients developed AKI with their first LAmB course

- The geometric mean eGFR in CPA patients was reduced post LAmB therapy 


\section{Introduction}

Intravenous amphotericin B therapy was first used for chronic pulmonary aspergillosis (CPA) in 1959, the first reported case of aspergillosis ever treated with amphotericin B [1]. A few subsequent reports have documented efficacy in a small number of patients, mostly treated with deoxycholate amphotericin B [2,3]. In contrast, there is extensive experience of amphotericin B for invasive pulmonary aspergillosis, including some randomised controlled trials [4-10] that show equivalent efficacy between different amphotericin B preparations with reduced toxicity of liposomal amphotericin B in most patients.

There are some specific potential advantages for amphotericin B for treating CPA. First, almost all the cases are caused by Aspergillus fumigatus. A. fumigatus is very rarely overtly resistant to amphotericin B unlike Aspergillus nidulans and Aspergillus terreus which are intrinsically resistant to amphotericin B (and may cause invasive aspergillosis) [11-15]. Second, triazole resistance is an increasing problem in A. fumigatus in many countries, especially northern Europe [16-20] and so intravenous therapy with either amphotericin B or an echinocandin are appropriate treatment options [21]. Third, CPA patients have subtle, poorly defined immunodeficiency [22-24] which may benefit from up-regulation of TH1 responses, which specifically liposomal amphotericin B does more so than deoxycholate amphotericin B [25].

Our prior small experience of treating CPA with deoxycholate amphotericin B was positive in terms of efficacy [2] but carried a major toxicity burden with $64 \%$ of patients having some significant adverse event over 3 weeks of therapy, if that length of therapy could even be delivered. About 5 years ago, we switched to liposomal amphotericin B (AmBisome) (LAmB) for all patients, with fewer toxicity issues. Here we report our clinical outcomes and adverse events with LAmB used to treat CPA.

CPA is usually a long-term progressive illness, causing either or both respiratory and systemic symptoms. As a result, different strategic approaches can be considered when using amphotericin therapy. The first approach is simply an initial, 'induction' course of therapy in newly diagnosed, but very ill patients with CPA. The logic for its use as initial therapy is to ensure IV treatment as opposed to oral delivery, to provide some 'immune stimulation' with upregulation of TH1 responses and to circumvent any concerns about triazole resistance. In patients with pan-azole resistant infection, a switch to intravenous echinocandin or amphotericin B is necessary, if any useful antifungal therapy is to be delivered. Such therapy 
could be delivered as occasional intravenous courses of therapy, or as continuous therapy. We have used both these longer term strategies and report both here.

\section{Patients and methods}

\section{Study design and data collection}

This audit was a retrospective case-note review of patients with CPA who received at least one short course of LAmB and any subsequent courses of treatment, under the care of the National Aspergillosis Centre (NAC) in Manchester, UK. CPA was defined using the definition described by Farid et al [26] and is consistent with the definition provided in the latest European Society for Clinical Microbiology and Infectious Diseases and European Respiratory Society guidelines [27]. Patients were eligible for inclusion in the audit if they had received one or more short courses of LAmB treatment, or a short course of LAmB treatment followed by intermittent long-term LAmB treatment, before July 2013. A short course of LAmB treatment was defined as daily treatment of less than six weeks in duration whilst intermittent long-term treatment was treatment given three to four times a week for at least 2 months duration. Intermittent long-term treatment was given for at least 2 months duration until the patient either did not require further antifungal therapy, clinically failed treatment or developed significant toxicities associated with their treatment. Intravenous LAmB was made up in normal saline and protected from the light. All patients received an initial test dose of $1 \mathrm{mg}$ of LAmB intravenously given over 10 - 15 minutes and if tolerated they received their treatment dose over $2-3.5$ hours.

A standardised proforma was used for data collection. Details recorded included patient demographics, co-existing respiratory illnesses in addition to their CPA, the main clinical indications for LAmB treatment including respiratory (cough, haemoptysis, shortness of breath including their MRC dyspnoea score if known ; $\mathrm{n}=3$ symptoms) and constitutional symptoms (weight loss, appetite, lethargy and fatigue, reported worsening quality of life (QOL); $\mathrm{n}=4$ symptoms), the use of intravenous fluid rehydration prior to commencing LAmB treatment, the use of amiloride or other diuretics, the dose and duration of LAmB therapy and whether dose modifications were made for renal toxicity reasons. Their pretreatment eGFR (estimated glomerular filtration rate), the lowest eGFR on LAmB treatment and their eGFR results at 1 month, 3 to 4 months and 6 to 8 months after treatment completion were recorded. Estimated eGFR measurements were calculated using the renal calculator found at www.egfrcacl.renal.org/. The risk of or development of an acute kidney injury (AKI) was defined using the RIFLE criteria where abrupt changes in renal function 
were of at least 24 hours in duration over 1 to 7 days [28]. Risk of AKI was defined as a decrease in eGFR of $>25 \%$ and injury occurred when the eGFR had fallen by $>50 \%$. Assessment of the risk and development of AKI was performed for all patients receiving their first course of LAmB treatment; this occurred for the duration of their therapy and for the following 7 days after their last dose of treatment. Information was collected on all potentially nephrotoxic medications and intravenous contrast media (for CT scan or bronchial artery embolization) given around the time of LAmB therapy. The development of chronic kidney disease (CKD) post LAmB therapy was defined using the categories of chronic kidney disease described in the KDIGO 2012, based on their eGFR [29]. The response to therapy was assessed in the 6 months following treatment and included collecting data on improvements in their respiratory and constitutional symptoms, their immunological and mycological response to treatment (if available) and their St George's respiratory Questionnaire QOL scores preand post-treatment (if available) [30].

\section{Treatment response in the six months after LAmB therapy}

Treatment responses were assessed in all patients who had received a minimum of three doses of LAmB therapy. A clinical response to treatment was defined as an improvement in at least two symptoms from the same symptom group; a $2 \mathrm{Kg}$ weight gain was used as the criteria for improvement in patients experiencing weight loss. Stable weight was defined as a change of $<2 \mathrm{Kg}$ in weight pre- and post-treatment and weight loss was defined a losing $>2 \mathrm{Kg}$ in weight. Improvements in haemoptysis were excluded from analysis if the patient had undergone bronchial artery embolization during LAmB therapy. An immunological response to treatment was defined as a four-fold drop in the Aspergillus precipitins antibody titre (Microgen, Camberley, UK) or a fall of $>50 \mathrm{mg} / \mathrm{L}$ in the Aspergillus specific IgG antibody titre (Phadia, Uppsala, Sweden). The mycological response was assessed in patients who had a positive sputum Aspergillus culture or Aspergillus PCR result prior to LAmB treatment. Fungal DNA extraction using MycXtra ${ }^{\mathrm{TM}}$ (Myconostica, Camberley, UK) and a commercial real time PCR assay, (MycAssay ${ }^{\mathrm{TM}}$ Aspergillus, Myconostica), which targets a portion of the $18 \mathrm{~S}$ ribosomal gene were done in the Mycology Reference Centre, Manchester. The failure to detect Aspergillus in their sputum, using the same methodology as their pre-treatment sample, post LAmB therapy was used to define a mycological response. Improvements in QOL were defined as an improvement of $\geq 4$ points in at least one modality (symptom, impact, activity, total) in the St George's QOL score [30]. A stable QOL score was defined as a change in score of less than 4 points in either direction whilst a deterioration was defined as an increase of $\geq 4$ points. 
All patients who received at least one full dose of LAmB therapy had their renal function assessed pre- and post-treatment. Patients who developed an AKI on LAmB therapy were given daily intravenous fluid (normal saline) rehydration and any concomitant nephrotoxic drugs stopped. Their renal function was closely monitored and in some instances the dose of LAmB given was reduced. The decision to dose reduce therapy and / or stop LAmB therapy was made by the treating physician on an individual basis although there was a general policy to stop treatment in the event that a patients' eGFR fell to $40 \mathrm{ml} / \mathrm{min} / 1.73 \mathrm{~m}^{2}$.

\section{Statistics}

Categorical data was reported as total numbers and percentages. Normally distributed and non-normally distributed data was reported as mean or median values respectively. Creatinine and eGFR data was $\log _{10}$ transformed prior to analysis to enable approximation to a normal distribution. A longitudinal regression analysis with linear response using generalised estimating equations with an autoregressive correlation structure was carried out to assess changes in creatinine and eGFR over time. For assessing the proportion of eGFR values below 90, a binary logistic response was used in the regression model.

\section{$\underline{\text { Results }}$}

Seventy one CPA patients (41 male, 30 female) were treated with LAmB therapy, of whom 20 patients had received 2 or more short courses and 5 patients had received at least one short course of treatment followed by intermittent long-term therapy. Their age ranged between 29 and 86 years (median 64 years) at the time of their first dose of LAmB therapy. Their baseline demographics, including underlying respiratory conditions apart from CPA and baseline renal function, is provided in Table 1. All but two patients had other underlying respiratory conditions, the commonest being a history of Mycobacterium tuberculosis or a nontuberculous mycobacterial infection, chronic pulmonary obstructive disease, bronchiectasis or interstitial lung disease. Three patients had received between one and three courses of intravenous amphotericin B therapy (each patient had received one course of LAmB) at their local hospital, prior to referral to the NAC. The median duration of prior azole therapy at the time of their first LAmB course was 12 months with 50 (70.4\%) patients having received two or more azoles in the past. Nineteen patients $(26.7 \%)$ had A. fumigatus in their sputum that was resistant to one or more azoles at the time of their first course of LAmB therapy. Ten (14.1\%) patients had infection with a pan-azole resistant $A$. fumigatus. The median duration of follow-up following their first course of LAmB therapy was 22 months (range $0-92$ 
months; $n=69$ patients). At the time this paper was written 35 (43.5\%) of the 69 patients who received at least 3 doses of $L A m B$ were still alive.

\section{Clinical indication and treatment response to the first short course of LAmB therapy}

The primary indication for treatment was either respiratory symptoms $(\mathrm{N}=33,46.5 \%$; mean number of symptoms was 2.34), constitutional symptoms $(\mathrm{N}=2,2.8 \%)$; mean number of symptoms was 2.17$)$ or both $(\mathrm{N}=36 ; 50.7 \%$; mean number of symptoms 4.51$)$. Two patients received treatment based primarily on their constitutional symptoms of weight loss and severe lethargy and fatigue.

Twenty seven (38\%) patients received intravenous fluid rehydration prior to their first few doses of LAmB therapy. The daily dose of LAmB given ranged between $2.5-5.0 \mathrm{mg} / \mathrm{kg} / \mathrm{day}$ (median $3.0 \mathrm{mg} / \mathrm{kg} /$ day). Two patients $(2.8 \%)$ were unable to tolerate the test dose of LAmB therapy and did not receive any further treatment. One additional patient suffered an acute fall in their eGFR by $35 \%$ within two days of starting therapy and did not receive any further treatment. This patient had not received IV fluid rehydration prior to their first dose of LAmB. The duration of therapy for the remaining patients $(n=68 ; 95.8 \%)$ ranged between 4 to 36 days (median 20.5 days).

The response to treatment was assessed in 65 patients. Six patients were excluded from the analysis; two patients were unable to tolerate LAmB, one patient had an acute drop to their eGFR and three patients started intermittent long-term LAmB treatment within one month of completing their first short course of LAmB therapy. Overall 48 patients $(73.8 \%)$ had a clinical response to treatment, as shown in Table 2. Improvements in respiratory symptoms were noted in 39 patients $(60 \%) ; 22$ of 29 (75.9\%) patients with pre- and post-treatment MRC dyspnoea scores experienced at least a 1 point improvement in their score. Thirty patients (46.2\%) noticed improvements in their constitutional symptoms with 27 (41.5\%) experiencing at least a $2 \mathrm{Kg}$ weight gain and $9(13.8 \%)$ gaining $>5 \mathrm{Kg}$ in weight. Improvements in both respiratory and constitutional symptoms were seen in 21 patients $(32.3 \%)$ whilst $27(41.5 \%)$ had a response in either their respiratory or constitutional symptoms. Seventeen patients (26.1\%) did not improve in either their respiratory or constitutional symptoms.

Sufficient data was available to assess the immunological response to treatment in 48 patients (73.8\%), 12 of whom (25\%) experienced a response to treatment. Seven patients had $A$. fumigatus cultured in their sputum just prior to LAmB therapy and following treatment the 
culture was negative in 2 patients $(28.6 \%)$. Thirteen patients had a positive sputum Aspergillus PCR pre-treatment and post-treatment the Aspergillus PCR was negative in 8 patients $(61.5 \%)$.

SGRQ QOL data was available in 40 patients pre- and post-treatment and 37 patients (92.5\%) noticed an improvement of 4 or more points in at least one modality. Improvements in the symptom, impact, activity and total scores are shown in Figure 1. A major 12 point improvement in each modality was seen in at least $30 \%$ of patients.

The clinical response to LAmB therapy was often delayed and only noticeable following completion of their LAmB treatment course. Thirty seven patients who responded to LAmB therapy did not receive an oral azole following their treatment course. The duration of their clinical response and remission ranged between $0-25$ months (median 4 months) after completing treatment; two patients started to deteriorate within $2-3$ weeks of finishing LAmB therapy.

\section{Clinical indication and treatment response to repeated short courses of LAmB therapy}

Twenty patients received two or more short-courses of LAmB therapy ( 2 courses, $n=14 ; 3$ courses, $n=5 ; 4$ courses, $n=1$; total number of courses given was 47 ). One patient received a short course of treatment, then intermittent long-term treatment followed by three further short courses of LAmB therapy; their intermittent long-term treatment had been stopped due to concerns about early clinical failure and renal toxicity. The median interval between each short course of treatment was 6 months (range 2-67 months, excluding the patient who received intermittent long-term treatment between their other short courses of treatment).The median duration of prior azole therapy at the time of their first course of LAmB therapy was 20.5 months (range 1 to 74 months) and 17 patients (85\%) had received prior treatment with two or more azoles.

The main indication for each short course of treatment $(n=47$ courses of treatment) was either respiratory symptoms $(\mathrm{N}=24,51.1 \%$; mean number of symptoms was 2.34$)$ or both respiratory and constitutional symptoms $(\mathrm{N}=23 ; 48.9 \%$; mean number of symptoms 4.55$)$. Eleven (55\%) of 20 patients had the same clinical indication for each course of treatment they received.

The daily dose of LAmB given ranged between $2.2-3.83 \mathrm{mg} / \mathrm{kg} /$ day (median 2.87 $\mathrm{mg} / \mathrm{kg} /$ day). The overall clinical response rate for the 47 short courses of LAmB given was 
76.6\% as shown in Table 3. Six (30\%) of 20 patients did not experience a clinical response to their first course of LAmB treatment but all six responded to a subsequent short course of treatment.

Improvements in respiratory symptoms were observed with 26 (55.3\%) courses of treatment; 10 of these courses $(38.5 \%)$ were associated with an improvement of at least 1 point in the patients' MRC dyspnoea score following treatment. Twenty four treatment courses (51.1\%) were associated with a response in constitutional symptoms; a weight gain of at least two kilograms was seen with 21 (44.7\%) courses of treatment and weight gain of over $5 \mathrm{Kg}$ was seen with $5(10.6 \%)$ treatment courses. Figure 2 illustrates the variable weight response observed between treatment courses for 13 patients who had at least 2 courses of LAmB treatment (courses received $=33$ ). The figure demonstrates their initial weight response to the first course of treatment and whether a similar response was observed with subsequent courses of treatment. Two patients lost weight with both treatment courses and in one patient his weight was stable with each treatment course. Five patients gained weight with each course of treatment whilst 8 patients had a variable weight response to the treatment courses they received.

Sufficient immunological data was available to assess the immunological response for 42 (89.4\%) of the 47 short courses of LAmB treatment. Nine patients (45\%) experienced an immunological response to treatment ( $\mathrm{n}=13$ courses) two of whom responded to both short courses of therapy. Five patients had a positive sputum culture for Aspergillus fumigatus prior to at least one $\mathrm{LAmB}$ course ( $\mathrm{n}=7$ courses of treatment) and following therapy all patients had a negative culture ( $\mathrm{n}=5$ courses of treatment). Seven patients had a positive Aspergillus $\mathrm{PCR}$ in at least one pre-treatment sputum sample ( $\mathrm{n}=11$ courses of treatment) and following treatment the sputum Aspergillus $\mathrm{PCR}$ was negative in five patients ( $\mathrm{n}=6$ courses of treatment; $54.5 \%$ of the treatment courses).

SGRQ QOL scores pre- and post-LAmB therapy were available for 36 courses of treatment $(\mathrm{n}=17$ patients) and a response in one or more modalities was observed with $33(91.7 \%)$ treatment courses. There were improvements in the symptom, impact, activity and total scores for $19(52.8 \%), 22(61.1 \%), 18(50.0 \%)$ and 21 (58.3\%) courses respectively; a major 12 point improvement was observed in these modalities in 14 (38.9\%), 15 (41.7\%), 16 (44.4\%) and $13(36.1 \%)$ treatment courses respectively. Thirteen patients had SGRQ QOL scores available pre- and post-treatment for at least two courses of treatment ( $\mathrm{n}=34$ courses). The variation in their QOL responses is shown in Figure 3. The majority of patients had a variable response in their QOL scores between treatment courses; a smaller proportion of patients 
showed a consistent improvement in one or more modalities of their SGRQ QOL score with repeated short courses of treatment.

\section{The treatment response to intermittent long-term LAmB therapy}

Five patients started long-term LAmB therapy within a month of completing a short course of treatment ( 3 patients after their first short course of therapy and 2 patients after their second short course of treatment). The main clinical indication for treatment was respiratory symptoms $(n=1)$, constitutional symptoms $(n=2)$ or both respiratory and constitutional symptoms $(n=2)$. Intermittent long-term treatment was generally given to patients who had no oral azole treatment options available due to either intolerance and /or resistance apart from one patient who had a major deterioration on itraconazole prior to receiving LAmB. This patient later tried voriconazole but was intolerant of it.

The dose of LAmB given as long-term treatment three times a week ranged between 2.53 $6.7 \mathrm{mg} / \mathrm{Kg} / \mathrm{dose}$ (mean $4 \mathrm{mg} / \mathrm{kg} /$ dose); the highest dose of $6.7 \mathrm{mg} / \mathrm{Kg} /$ dose was given to a patient who had a multi-azole resistant Aspergillus fumigatus infection that had not been controlled on a dose of $5.4 \mathrm{mg} / \mathrm{kg} /$ dose of LAmB given three times a week. The duration of treatment ranged between 4 and 24 months (median 11 months).

All five patients showed a clinical response to treatment. Four patients had an improvement in their chest symptoms and three patients noticed an improvement in their constitutional symptoms. The mean number of symptoms that improved was 3.8 (range $3-5$ symptoms) and two $(40 \%)$ patients experienced an immunological response to treatment. Four patients later failed LAmB and one patient stopped long-term therapy following a completion pneumonectomy. Two patients subsequently died with CPA and end stage respiratory disease.

\section{Acute kidney injury associated with LAmB therapy}

The majority of patients had either normal renal function (grade $1 \mathrm{CKD} ; \mathrm{n}=48,67.7 \%$ ) or mild renal impairment (grade $2 \mathrm{CKD} ; \mathrm{n}=20,28.2 \%$ ) prior to their first course of LAmB therapy. There were three (4.2\%) patients who had stage $3 \mathrm{a}$ CKD prior to treatment, as shown in Table 1. 


\section{a) Renal function following first short course of LAmB therapy}

Changes in eGFR were commonly seen in patients receiving their first short course of LAmB therapy. Fifty one of 68 (75\%) patients experienced a fall of over $25 \%$ in their eGFR during their first course of therapy, resulting in an increased risk of AKI, of whom 17 (25\%) patients developed an AKI with treatment. One patient was excluded from the analysis as he had short courses of treatment before and following intermittent long-term LAmB therapy. Figures $4 \mathbf{A}$ and 4B illustrates the proportion of patients who developed an increased risk of AKI or AKI during their first course of LAmB therapy; the largest proportion of patients had a fall of $>25 \%$ in their eGFR during their second week of treatment. The use of intravenous fluid rehydration therapy prior to the first few doses of LAmB therapy did not reduce the proportion of patients who developed increased risk of AKI or an AKI; 7 (25.9\%) out of 27 patients with intravenous rehydration maintained their renal function throughout their course of treatment compared to $11(26.8 \%)$ of 41 patients who did not receive pre-treatment intravenous fluid rehydration.

Twenty four (35.3\%) of the 68 patients treated with LAmB had at least one other contributing factor to the development of an increased risk of AKI or an AKI. Seventeen (25\%) patients had received intravenous contrast and of these patients 9 (52.9\%) developed an increased risk of AKI and 5 (29.4\%) an AKI. Nine (13.2\%) of 68 patients were receiving other concomitant medications with associated nephrotoxicity risks (NSAIDs, $\mathrm{n}=1$; polymyxin, $\mathrm{n}=1$; acyclovir, $\mathrm{n}=1$; aminoglycosides, $\mathrm{n}=6$ ) and all these individuals experienced either an increased risk of AKI $(n=6)$ or an AKI $(n=3)$. In total $8(15.7 \%)$ of 51 patients with either an increased risk of AKI or AKI stopped their LAmB therapy early, despite 4 having a LAmB dose reduction prior to stopping treatment.

An overall deterioration in renal function was observed in patients during and following their first course of LAmB therapy, as shown in Figures 5A and Figure 5B. The adjusted geometric mean eGFR fell during treatment and did improve post treatment but did not return to pre-treatment levels $(\mathrm{p}<0.001)$. The adjusted percentage of individuals with an eGFR $<90$ increased following treatment and this was also statistically significant $(p<0.001)$.

\section{b) Renal function following the second short course of LAmB therapy}

Nineteen patients had their renal function assessed prior to and following their second course of treatment. Figures 6A and 6B show the adjusted geometric mean eGFR and adjusted percentage of individuals with an eGFR $<90$ during and following their second course of 
LAmB therapy $(n=19)$. There was a statistically significant decline in the adjusted geometric mean eGFR over the time-frame illustrated $(p<0.001)$ but no change in the adjusted percentage of individuals with an eGFR $<90$ following treatment $(\mathrm{p}=0.57)$. On reviewing their renal function prior to their first course of LAmB therapy there were 11 patients with normal renal function (grade $1 \mathrm{CKD}$ ), 7 patients with mild renal impairment (grade $2 \mathrm{CKD}$ ) and 1 patient with grade $3 \mathrm{CKD}$. Following their second course of treatment 8,9 and 2 patients respectively had grade 1 , grade 2 and grade 3 CKD indicating that a proportion of patients had developed worsening CKD following their two courses of LAmB therapy.

\section{c) Renal function with long-term interment LAmB therapy}

Five patients had intermittent long-term LAmB therapy, three of whom had stable renal function throughout treatment. Two patients stopped treatment due to worsening renal function. One patient developed Stage $4 \mathrm{CKD}$ and nephrogenic diabetes and the remaining patient had deteriorating renal function (Stage 3A to Stage 3B) despite a dose reduction in LAmB.

\section{Conclusion}

In last 40 years, amphotericin B has been frequently used for the treatment of invasive aspergillosis (IA) with modest outcomes [31]. Pulmonary localization of infection carried a medium likelihood of survival compared with brain or sinus infection, with an overall survival rate of $14 \%$ in collected series [31]. In a small prospective randomized study completed in 1991, 28 neutropenic patients with IA were given deoxycholate amphotericin B with or without flucytosine, only 5 survived (17.9\%) [4]. The relatively low response and survival rates showed some improvement in a prospective randomized controlled study comparing deoxycholate and colloidal dispersion formulations completed in 1997 [9]. Highly immunocompromised patients including $42 \%$ allogeneic hematopoetic stem cell transplant recipients enrolled without antigen, PCR or CT scanning criteria alone (and therefore often late diagnoses) had a $13.8 \%$ response rate and a $47.3 \% 12$ week survival rate. The registration studies for voriconazole utilized deoxycholate amphotericin B, and found an overall survival rate of $57.9 \%$ at 12 weeks, with $80.5 \%$ of patients switching to alternative therapy, usually a lipid formulation of amphotericin B in those commenced on deoxycholate amphotericin B [8]. In the 26 patients who only received deoxycholate amphotericin B, $1(4 \%)$ responded to therapy [32]. This randomised study enrolled haematology patients on the basis of CT scan appearances only, without antigen detection. A later study almost exclusively in the 'good' prognostic group of acute leukaemia utilized both CT scanning and antigen detection for 
enrolment [10]. Here $65.7 \%$ of patients survived to 12 weeks, considerably better than in prior studies, probably primarily because of earlier diagnosis, lower intensity hematopoetic stem cell transplantation and neutrophil recovery. This trend towards improved outcomes has also been noted in large collected series with typically $45 \%$ of patients treated with any amphotericin B formulation surviving to 12 weeks [33].

The situation in CPA is different because patients are not immunocompromised and there is no expectation of an overt change in immune status during treatment, as with neutrophil recovery. Therefore one might expect improved response rates. However in IA treatment studies, the key determinants of outcome are survival and radiographic improvement, neither of which pertain to CPA in a 3 week time frame of amphotericin B therapy. So therapeutic response is assessed on the basis of a quality of life scores, weight gain, general symptoms and downward trends in Aspergillus antibody titres and inflammatory markers and sputum culture or PCR conversion to negative. Here, $75 \%$ of those treated with LAmB improved clinically, to variable degrees, with both their first and subsequent treatment courses. This response rate is similar to those treated with deoxycholate amphotericin B (82\% improved or stable) [2]. All patients on long-term intermittent LAmB demonstrated a clinical response.

Several studies have demonstrated that LAmB has less nephrotoxic effects than conventional amphotericin B in the presence or absence of other concomitant nephrotoxic drugs [9, 34,35]. The proportion of patients experiencing significant nephrotoxicity during treatment with intravenous amphotericin B (conventional or liposomal) increased with the addition of one or more concomitant nephrotoxic medications $[34,36]$. These studies defined significant nephrotoxicity as either reaching an absolute peak serum creatinine level of 265umol/L [34] or a doubling or tripling of baseline serum creatinine levels during LAmB therapy [34-36]. Walsh et al [34] described significant nephrotoxicity in 33.7\% of patients receiving 0.6 $\mathrm{mg} / \mathrm{Kg} /$ day of conventional amphotericin B compared to $18.7 \%$ of patients treated with 3 $\mathrm{mg} / \mathrm{kg} /$ day of LAmB. In the study of Prentice et al [35] in leukaemia patients, nephrotoxicity was observed in $24 \%$ of patients on $1 \mathrm{mg} / \mathrm{Kg} /$ day of conventional amphotericin B compared to $12 \%$ of patients receiving $3 \mathrm{mg} / \mathrm{Kg} /$ day of $\mathrm{LAmB}$. The different liposomal preparations of amphotericin $\mathrm{B}$ have been shown by Wingard et al [36] to have differing nephrotoxicity rates; treatment with $3 \mathrm{mg} / \mathrm{Kg} / \mathrm{day}$ or $5 \mathrm{mg} / \mathrm{Kg}$ /day of $\mathrm{LAmB}$ was associated with nephrotoxicity in $14 \%$ of patients compared to $42 \%$ of patients treated with amphotericin B lipid complex at a dose of $5 \mathrm{mg} / \mathrm{kg} /$ day. If we had used a definition of significant nephrotoxicity of a peak serum creatinine level of $265 \mathrm{umol} / \mathrm{L}$, then no patients would be defined as having significant 
nephrotoxicity with one or more treatment courses with $3 \mathrm{mg} / \mathrm{Kg} /$ day $\mathrm{LAmB}$ or only $17.4 \%$ if a doubling of serum creatinine was used to define nephrotoxicity.

The estimated glomerular filtration rate is now used as the main tool to assess renal function, both in AKI and CKD. Deterioration in renal function was commonly seen during LAmB therapy whether or not patients received pre-rehydration with intravenous fluids. Fifty one of 68 (75\%) patients experienced a fall in their eGFR of over $25 \%$ during their first course of therapy resulting in an increased risk of AKI, according to the RIFLE criteria [28], in 34 (50\%) patients and an AKI in 17 (25\%) patients. Twenty four (35.3\%) of 68 patients had at least one other contributing factor to the development of an increased risk of AKI or an AKI; 17 (25\%) patients had a contrast scan and $9(13.2 \%)$ patients were receiving potentially nephrotoxic medications. Only $3(12.5 \%)$ of 24 patients with an additional potential nephrotoxicity risk avoided an increased risk of AKI or AKI during their LAmB treatment. The deterioration in renal function observed during and following the first course of LAmB therapy was statistically significant; both the geometric mean eGFR fell and the adjusted percentage of individuals with an eGFR $<90$ (equivalent to CKD Stage 2 or more) significantly increased (both $\mathrm{p}$ values were $<0.001$ ). A similar deterioration in the adjusted geometric mean eGFR was observed for the 19 patients who received a second short course of LAmB therapy $(\mathrm{p}<0.001)$ although there was no significant change in the percentage of individuals with an eGFR $<90(\mathrm{p}=0.57)$. There was a higher proportion of patients with grade 2 and grade $3 \mathrm{CKD}$ after their second course of LAmB treatment.

Avoidance of intravenous contrast (for CT scans or bronchial artery embolization) or other medications with known associated nephrotoxicity is prudent during LAmB therapy. Nacetylcysteine may ameliorate nephrotoxicity as shown by Karimzadeh et al [37] in a double blind placebo controlled study ( $\mathrm{p}=0.049)$, at the cost of increased other adverse reactions.

Here we document that repeated short courses of LAmB therapy are associated with deterioration in renal function, as determined by a fall in the adjusted geometric mean eGFR following treatment. It raises the question of whether repeated courses of LAmB to control CPA disease should be avoided, if other intravenous therapies such as echinocandins are a treatment option. However the response rate to $\mathrm{LAmB}$ was generally good, with clinical benefit of some level in most patients. Comparative studies with other agents are necessary to truly compare response and toxicity, but this large retrospective series sets the stage for such studies by providing effect estimates that can be used for estimating study size for different endpoints. 


\section{Acknowledgements}

We would like to thank Georgina Powell, Deborah Kennedy, Deborah Hawker, Stephanie

Polisena and Graham Atherton for their support in analysing the SGRQ QOL questionnaires.

\section{Funding}

This audit was not funded externally. In particular there has been no involvement of Gilead Sciences in any aspect of this work.

\section{Potential conflict of interest}

PJN has received travel costs and meeting / conference fees from MSD, BMS, Gilead, and Johnson and Johnson in the last 3 years. CH and JM report no potential conflicts of interest. Dr Denning holds Founder shares in F2G Ltd a University of Manchester spin-out antifungal discovery company, in Novocyt which markets the Myconostica real-time molecular assays and has current grant support from the National Institute of Health Research, NorthWest Lung Centre Charity, Medical Research Council and the Fungal Infection Trust. He acts or has recently acted as a consultant to Astellas, Sigma Tau, Basilea, Scynexis, Cidara and Pulmocide. In the last 3 years, he has been paid for talks on behalf of Astellas, Dynamiker, Gilead, Merck and Pfizer. He is also a member of the Infectious Disease Society of America Aspergillosis Guidelines and European Society for Clinical Microbiology and Infectious Diseases Aspergillosis Guidelines groups. 


\section{References:}

1. Kelmenson VA. Treatment of pulmonary aspergillosis. Dis Chest 1959; 36: 442-443.

2. Denning DW, Riniotis K, Dobrashian R, Sambatakou H. Chronic cavitary and fibrosing pulmonary and pleural aspergillosis: case series, proposed nomenclature change, and review. Clin Infect Dis 2003; 37 (Suppl 3): S265-80.

3. Nam HS, Jeon K, Um SW, Suh GY, Chung MP, Kim H, Kwon OJ, Koh WJ. Clinical characteristics and treatment outcomes of chronic necrotizing pulmonary aspergillosis: a review of 43 cases. Int J Infect Dis 2010; 14: e479-82.

4. Verweij PE, Donnelly JP, Kullberg BJ, Meis JF, De Pauw BE. Amphotericin B versus amphotericin B plus 5-flucytosine: poor results in the treatment of proven systemic mycoses in neutropenic patients. Infection 1994; 22 (2): 81-5.

5. Van't Wout JW, Novakova I, Verhagen CAH, Fibbe WE, De Pauw BE, Van der Meer JWM. The efficacy of itraconazole against systemic fungal infections in neutropenic patients: a randomised comparative study with amphotericin B. J Infect 1991; 22: 45-52.

6. Ellis M, Spence D, de Pauw B, et al. An EORTC international multicenter randomized trial (EORTC number 19923) comparing two dosages of liposomal amphotericin B for treatment of invasive aspergillosis. Clin Infect Dis 1998; 27: 1406-12.

7. Leenders AC, Daenen S, Jansen RLH, et al. Liposomal amphotericin B compared with amphotericin B deoxycholate in the treatment of documented and suspected neutropeniaassociated invasive fungal in- fections. Br J Haematol 1998; 103:205-12.

8. Herbrecht R, Denning DW, Patterson TF, Bennett JE, Greene RE, Oestmann JW, Kern W, Marr KA, Ribaud P, Lortholary O,Sylvester R, de Pauw B, Rubin RH, Wingard JR, Stark PS, Durand C, Caillot D, Thiel E, Chandrasekar PH, Hodges MR, Schlamm HT, Troke $\mathrm{PF}$. Randomised comparison of voriconazole and amphotericin B in primary therapy of invasive aspergillosis. N Engl J Med 2002; 347: 408-15.

9. Bowden R, Chandrasekar P, White MH, Li X, Pietrelli L, Gurwith M, van Burik JA, Laverdiere M, Safrin S, Wingard JR. A double-blind, randomized, controlled trial of amphotericin B colloidal dispersion versus amphotericin B for treatment of invasive aspergillosis in immunocompromised patients. Clin Infect Dis 2002; 35(4): 359-66.

10.Cornely OA, Maertens J, Bresnik M, Ebrahimi R, Ullmann AJ, Bouza E, Heussel CP, Lortholary O, Rieger C, Boehme A, Aoun M, Horst HA, Thiebaut A, Ruhnke M, Reichert D, Vianelli N, Krause SW, Olavarria E, Herbrecht R; AmBiLoad Trial Study Group. Liposomal amphotericin $\mathrm{B}$ as initial therapy for invasive mold infection: a randomized trial comparing a high-loading dose regimen with standard dosing (AmBiLoad trial). Clin Infect Dis. 2007; 44: 1289-97.

11.Lewis RE, Albert NP, Liao G, Wang W, Prince RA, Kontoyiannis DP. High-dose induction liposomal amphotericin B followed by de-escalation is effective in experimental Aspergillus terreus pneumonia. J Antimicrob Chemother. 2013; 68:1148-51.

12.Blum G, Hörtnagl C, Jukic E, Erbeznik T, Pümpel T, Dietrich H, Nagl M, Speth C, Rambach G, Lass-Flörl C. New insight into amphotericin B resistance in Aspergillus terreus. Antimicrob Agents Chemother 2013; 57:1583-8. 
13.Palaez T, Guinea J, Gama B, Flores R, Recio S, Torres-Narbona M, Munoz P, Bouza E. Is Aspergillus nidulans susceptible to all antifungal agents? In Vitro activity of an updated panel of antifungal agents against 63 clinical isolates. 2009. ECCMID abstract 13401.

14.Segal BH, DeCarlo ES, Kwon-Chung KJ, Malech HL, Gallin JI, Holland SM. Aspergillus nidulans infection in chronic granulomatous disease. Medicine (Baltimore) 1998; 77:34554.

15.Alastruey-Izquierdo A, Alcazar-Fuoli L, Cuenca-Estrella M. Antifungal susceptibility profile of cryptic species of Aspergillus. Mycopathologia 2014; 178: 427-33.

16.Kikuchi K, Watanabe A, Ito J, Oku Y, Wuren T, Taguchi H, Yarita K, Muraosa Y, Yahiro M, Yaguchi T, Kamei K. Antifungal susceptibility of Aspergillus fumigatus clinical isolates collected from various areas in Japan. J Infect Chemother 2014; 20(5): 336-8.

17.Vermeulen E, Lagrou K, Verweij PE. Azole resistance in Aspergillus fumigatus: a growing public health concern. Curr Opin Infect Dis 2013 Dec; 26(6): 493-500.

18.Denning DW, Bowyer P. Voriconazole resistance in Aspergillus fumigatus - should we be concerned? Commentary. Clin Infect Dis 2013;57: 521-3.

19. Bowyer P, Denning DW. Fungicides and triazole resistance in Aspergillus. Pest Manag Sci 2014; $70: 173-8$.

20.Fuhren J, Voskuil WS, Boel CH, Haas PJ, Hagen F, Meis JF, Kusters JG. High prevalence of azole resistance in Aspergillus fumigatus isolates from high-riskpatients. J Antimicrob Chemother. 2015: Jul 9. pii: dkv177. [Epub ahead of print] PubMed PMID: 26163402.

21.Verweij PE, Ananda-Rajah M, Andes D, Arendrup MC, Brüggemann RJ, Chowdhary A, Cornely OA, Denning DW, Groll AH, Izumikawa K, Kullberg BJ, Lagrou K, Maertens J, Meis JF, Newton P, Page ID, Seyedmousavi S, Sheppard DC, Viscoli C, Warris A, DonnellyJP. International expert opinion on the management of infection caused by azoleresistant Aspergillus fumigatus. Drug Res Updates 2015; Jul - Aug 21 -22: 30 - 40.

22. Sambatakou H, Pravica V, Hutchinson I, Denning DW. Cytokine profiling of pulmonary aspergillosis. Int J Immunogenetics 2006:33; 297-302.

23. Smith NL, Bowyer P, Simpson A, Hankinson J, Denning DW. A prominent role for IL1 pathway and IL15 in susceptibility to chronic cavitary pulmonary aspergillosis. Clin Microbiol Infect 2014; 20(8):O480-8.

24. Smith NS, Bowyer P, Simpson A, Hankinson J, Denning DW. Reduced expression of TLR3, TLR10 and TREM1 by macrophages in CCPA, and novel genetic associations of VEGFA, DENND1B and PLAT with this disease. Clin Microbiol Infect 2014; 20: O9608.

25.Bellocchio S, Gaziano R, Bozza S, Rossi G, Montagnoli C, Perruccio K, Calvitti M, Pitzurra L, Romani L. Liposomal amphotericin B activates antifungal resistance with reduced toxicity by diverting Toll-like receptor signalling from TLR-2 to TLR-4. J Antimicrob Chemother 2005; 55: 214-22.

26.Farid S, Mohammed S, Devbhandari M, Soon S, Jones MT, Krysiak P, Shah R, Kneale M, Richardson MD, Denning DW, Rammohan KS. Surgery for chronic pulmonary aspergillosis, risk stratification and recurrence - A National Centre's experience. J Cardiothorac Surg 2013; 8:180. 
27.Denning DW, Cadranel J, Beigelman-Aubry C, Ader, F, Chakrabarti A, Blot S, Ullman A, Dimopoulos G, Lange C. Chronic pulmonary aspergillosis - Rationale and clinical guidelines for diagnosis and management. Eur Resp J 2016; 47:45-68.

28.KDIGO $2012^{\mathrm{A}}$ Clinical Practice Guideline for Acute Kidney Injury. Kidney International. 2012; 2 (Supplement 1).

29.KDIGO $2012^{\mathrm{B}}$ Clinical Practice Guideline for the Evaluation and Management of Chronic Kidney Disease. Kidney International. 2013; 3(Supplement 1).

30.Al-shair K, Atherton GTW, Harris C, Ratcliffe L, Newton P, Denning DW. Long-term antifungal treatment improves health status in patients with chronic pulmonary aspergillosis; a longitudinal analysis. Clin Infect Dis 2013; 57: 828-35

31.Denning DW. Therapeutic outcome of invasive aspergillosis. Clin Infect Dis 1996; 23: 608-615.

32.Patterson TF, Boucher HW, Herbrecht R, Denning DW, Lortholary O, Ribaud P, Rubin RH, Wingard JR, DePauw B, Schlamm HT, Troke PF, Bennett JE. The Strategy of Following Voriconazole versus Amphotericin B with Other Licensed Antifungal Therapy for Primary Therapy of Invasive Aspergillosis: Impact of Other Therapies on Outcome. Clin Infect Dis 2005; 41:1448-52.

33.Nivoix Y, Velten M, Letscher-Bru V, Moghaddam A, Natarajan-Amé S, Fohrer C, Lioure B, Bilger K, Lutun P, Marcellin L, Launoy A, Freys G, Bergerat JP, Herbrecht R. Factors associated with overall and attributable mortality in invasive aspergillosis. Clin Infect Dis 2008; 47: 1176-84.

34.Walsh TJ, Finberg RW, Arndt C, Hiemenz J, Schwartz C, Bodensteiner D, Pappas P, Seibel N, Greenberg RN, Dummer S, Schuster M, Holcenberg JS for the National Institute of Allergy and Infectious Diseases Mycoses Study Group. New Eng J Med 1999; 340: 764 -71 .

35.Prentice HG, Hann IM, Herbrecht R, Kvaloy S, Catocsky D, Pinkerton CR, Schey SA, Jacobs F, Oakhill A, Stevens RF, Darbyshire PJ and Gibson BES. A randomised comparison of liposomal versus conventional amphotericin B for the treatment of pyrexia of unknown origin in neutropenic patients. Brit J Haem. 1997. 98: 711-718

36.Wingard JR, White MH, Anaissie E, Raffalli J, Goodman J, Arrieta A and the L Amph/ABLC collaborative Study Group. A randomised, double-blind comparative trial evaluating the safety of liposomal Amphotericin B versus amphotericin B lipid complex in the empirical treatment of febrile neutropenia. Clin Infect Dis 2000 31: 1155-63.

37.Karimzadeh I, Khalili H, Sagheb MM and Farsaei S. A double-blinded placebo-controlled, multicenter clinical trial of $\mathrm{N}$-acetylcysteine for preventing amphotericin $\mathrm{B}$-induced nephrotoxicity. Expert Opin. Drug Metab. Toxicol. 2015 (early online version -11 pages). 
Table 1

Baseline demographics and patient characteristics at the time they received their first course of IV LAmB therapy.

\begin{tabular}{|c|c|}
\hline Variable & Number (\% or median) \\
\hline Sex $(M)(\%)$ & $41(57.7 \%)$ \\
\hline Age (years) & $29-86($ median 64) \\
\hline $\begin{array}{l}\text { Underlying respiratory disease } \\
\text { Mycobacterial infection (TB/NTM) } \\
\text { COPD } \\
\text { ABPA with Asthma } \\
\text { Asthma with no ABPA } \\
\text { Bronchiectasis } \\
\text { Previous pneumothorax } \\
\text { Previous thoracic surgery } \\
\text { Lung cancer } \\
\text { Previous thoracic radiotherapy } \\
\text { Interstitial lung disease } \\
\text { Other* } \\
\text { None }\end{array}$ & $\begin{array}{l}20(28.2 \%) \\
20(28.2 \%) \\
9(12.7 \%) \\
4(5.6 \%) \\
15(21.1 \%) \\
9(12.7 \%) \\
6(8.4 \%) \\
4(5.6 \%) \\
4(5.6 \%) \\
13(18.3 \%) \\
6(8.4 \%) \\
2(2.8 \%) \\
\end{array}$ \\
\hline $\begin{array}{l}\text { Duration of previous azole therapy }(\mathrm{n}=71 \text { patients }) \\
\text { Itraconazole }(\mathrm{N}=62 \text { patients }) \\
\text { Voriconazole }(\mathrm{N}=53 \text { patients }) \\
\text { Posaconazole }(\mathrm{N}=29 \text { patients })\end{array}$ & $\begin{array}{l}0-112 \text { months (median } 12) \\
1-67 \text { months (median 7) } \\
1-55 \text { months (median 6.5) } \\
1-43 \text { months (median } 11)\end{array}$ \\
\hline Main indication for discontinuing prior azole therapy & \\
\hline $\begin{array}{l}\text { Itraconazole }(\mathrm{N}=62 \text { patients }) \\
\text { Intolerance and / or toxicity } \\
\text { Clinical failure and / or documented resistance }\end{array}$ & $\begin{array}{l}\mathrm{N}=30(48.4 \%) \\
\mathrm{N}=35(56.4 \%) \text {; documented } \\
\text { resistance was seen in } 19 \\
(30.6 \%) \text { patients }\end{array}$ \\
\hline $\begin{array}{l}\text { Voriconazole ( } \mathrm{n}=53 \text { patients) } \\
\text { Intolerance and / or toxicity } \\
\text { Clinical failure and / or documented resistance }\end{array}$ & $\begin{array}{l}\mathrm{N}=42(79.2 \%) \\
\mathrm{N}=28(52.8 \%) ; \text { documented } \\
\text { resistance was seen in } 14 \\
(26.4 \%) \text { patients }\end{array}$ \\
\hline $\begin{array}{l}\text { Posaconazole }(\mathrm{N}=29 \text { patients }) \\
\text { Intolerance and / or toxicity } \\
\text { Clinical failure and / or documented resistance }\end{array}$ & $\begin{array}{l}\mathrm{N}=8(27.6 \%) \\
\mathrm{N}=18(62.1 \%) \text {; documented } \\
\text { resistance was seen in } 12 \\
(41.4 \%) \text { patients }\end{array}$ \\
\hline Treatment changed due to funding issues & $\mathrm{N}=3(10.3 \%)$ \\
\hline $\begin{array}{l}\text { Baseline renal function** } \\
\text { Grade } 1 \\
\text { Grade } 2 \\
\text { Grade } 3 \mathrm{a} \\
\text { Grade } 3 \mathrm{~b} \text { to Grade } 5\end{array}$ & $\begin{array}{l}\mathrm{N}=48 \\
\mathrm{~N}=20 \\
\mathrm{~N}=3 \\
\mathrm{~N}=0\end{array}$ \\
\hline
\end{tabular}


Abbreviations:

TB, Tuberculosis; NTM, Non tuberculous mycobacterial infection; COPD, Chronic obstructive pulmonary disease; ABPA, Allergic bronchopulmonary aspergillosis.

* includes severe pneumonia requiring admission to intensive care $(\mathrm{n}=3)$, extrinsic allergic alveolitis $(\mathrm{n}=1)$, exposure to silica $(\mathrm{n}=1)$ and congenital cystic lung disease $(\mathrm{n}=1)$

** According to KDIGO 2012 categories of chronic kidney disease (KDIGO 2012 ${ }^{\mathrm{B}}$ ) 
Table 2

The clinical response to the first short course of LAmB therapy.

\begin{tabular}{|l|l|l|}
\hline $\begin{array}{l}\text { Clinical response observed } \\
\text { in the symptom group }\end{array}$ & $\begin{array}{l}\text { Mean number of symptoms } \\
\text { that improved }\end{array}$ & $\begin{array}{l}\text { Number (\%) of patients } \\
\text { that responded }\end{array}$ \\
\hline Respiratory* & 1.88 & $39(60.0 \%)$ \\
\hline Constitutional & 1.98 & $30(46.1 \%)$ \\
\hline $\begin{array}{l}\text { Both respiratory and } \\
\text { constitutional }\end{array}$ & 3.17 & $21(32.3 \%)$ \\
\hline $\begin{array}{l}\text { Either respiratory or } \\
\text { constitutional }\end{array}$ & 2.81 & $27(41.5 \%)$ \\
\hline No response & 1.12 & $17(26.1 \%)$ \\
\hline
\end{tabular}

* Nine patients with haemoptysis underwent bronchial artery embolization whilst receiving LAmB therapy. 
Table 3

The clinical response to repeated short courses of LAmB therapy.

\begin{tabular}{|l|l|l|}
\hline $\begin{array}{l}\text { Clinical response } \\
\text { observed in the symptom } \\
\text { group* }\end{array}$ & $\begin{array}{l}\text { Mean number of } \\
\text { symptoms that improved } \\
\text { with each course of } \\
\text { treatment }\end{array}$ & $\begin{array}{l}\text { Number (\%) of } \\
\text { treatment courses where } \\
\text { a clinical response was } \\
\text { observed }\end{array}$ \\
\hline Respiratory & 1.68 & $26(55.3 \%)$ \\
\hline Constitutional & 1.63 & $24(51.1 \%)$ \\
\hline $\begin{array}{l}\text { Both respiratory and } \\
\text { constitutional }\end{array}$ & 3.26 & $15(31.9 \%)$ \\
\hline $\begin{array}{l}\text { Either respiratory or } \\
\text { constitutional }\end{array}$ & 3.0 & $21(44.7 \%)$ \\
\hline No response & 1.36 & $11(23.4 \%)$ \\
\hline
\end{tabular}

*Twenty patients received two or more short-courses of LAmB therapy ( 2 courses, $n=14 ; 3$ courses, $n=5 ; 4$ courses, $n=1$; total number of courses given was 47 ). This table summarises the clinical response to LAmB therapy for all the courses of treatment they received. 


\section{Figure 1}

Changes in the St George's Respiratory Questionnaire QOL score after LAmB treatment in 40 patients

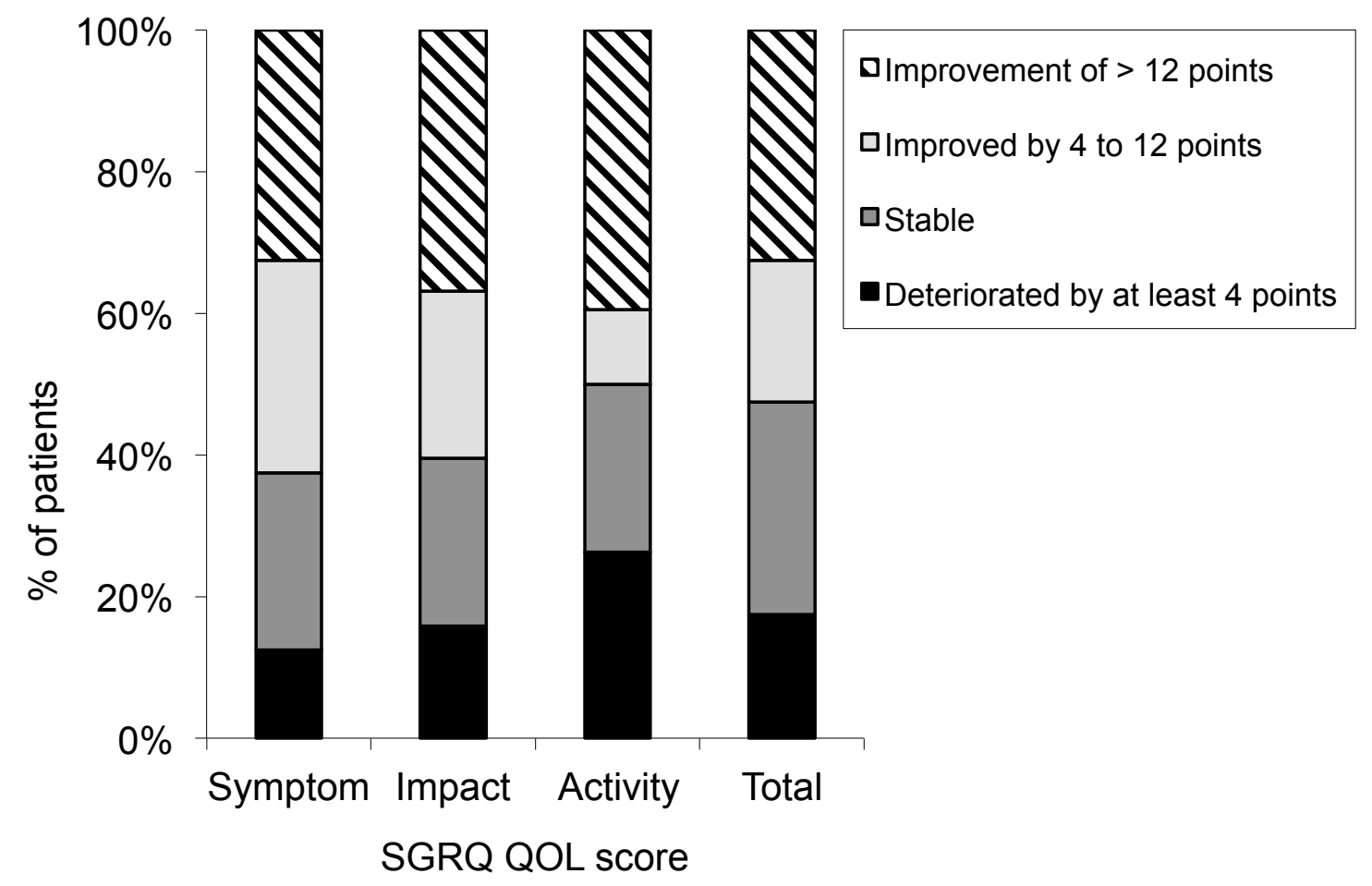


Figure 2

A $5 \mathrm{Kg}$ weight change following repeated courses of LAmB treatment in 13 patients.

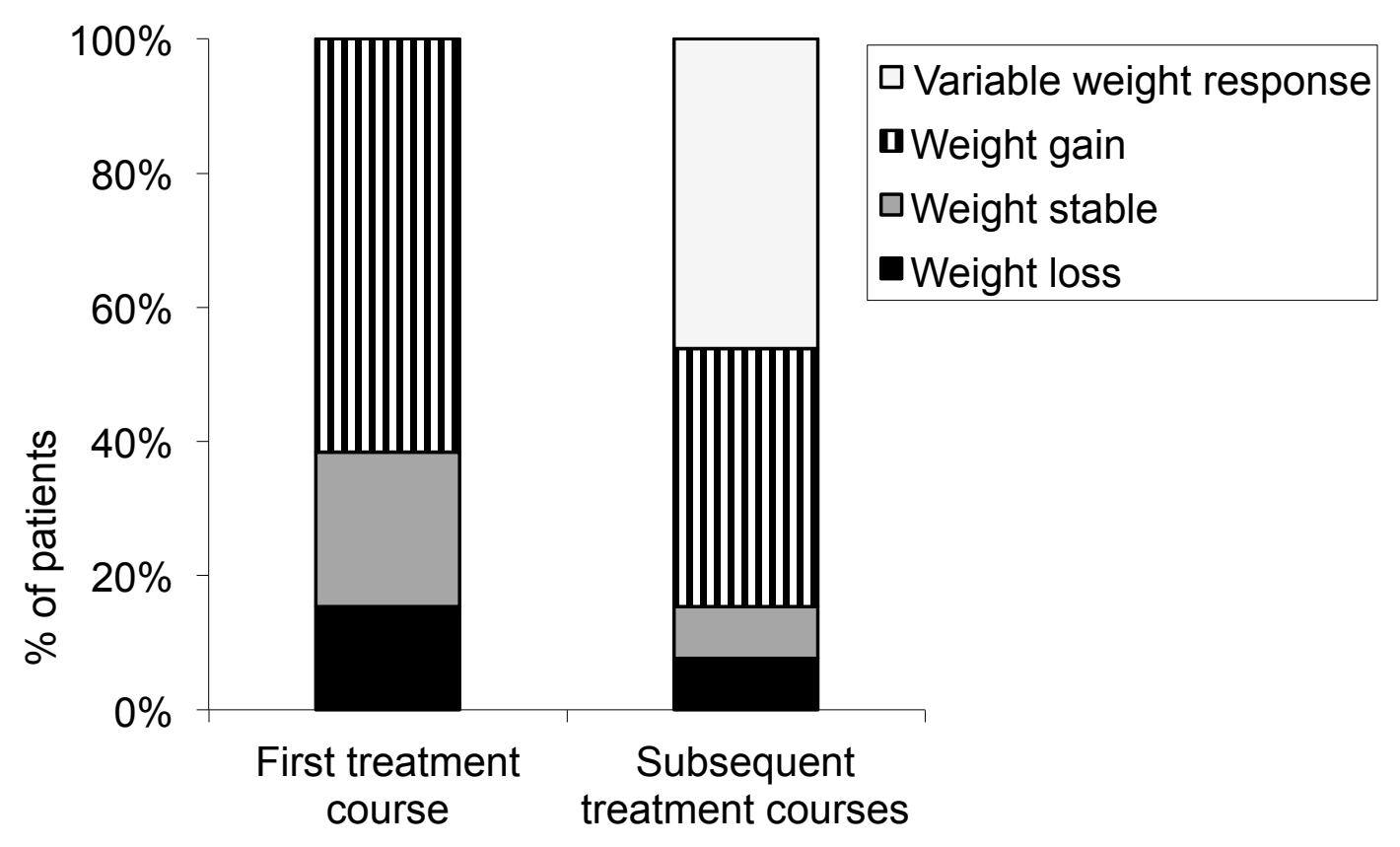

Weight response with IV LAmB treatment 
Figure 3

St George's Respiratory Questionnaire QOL changes following repeated courses of LAmB treatment in 13 patients.

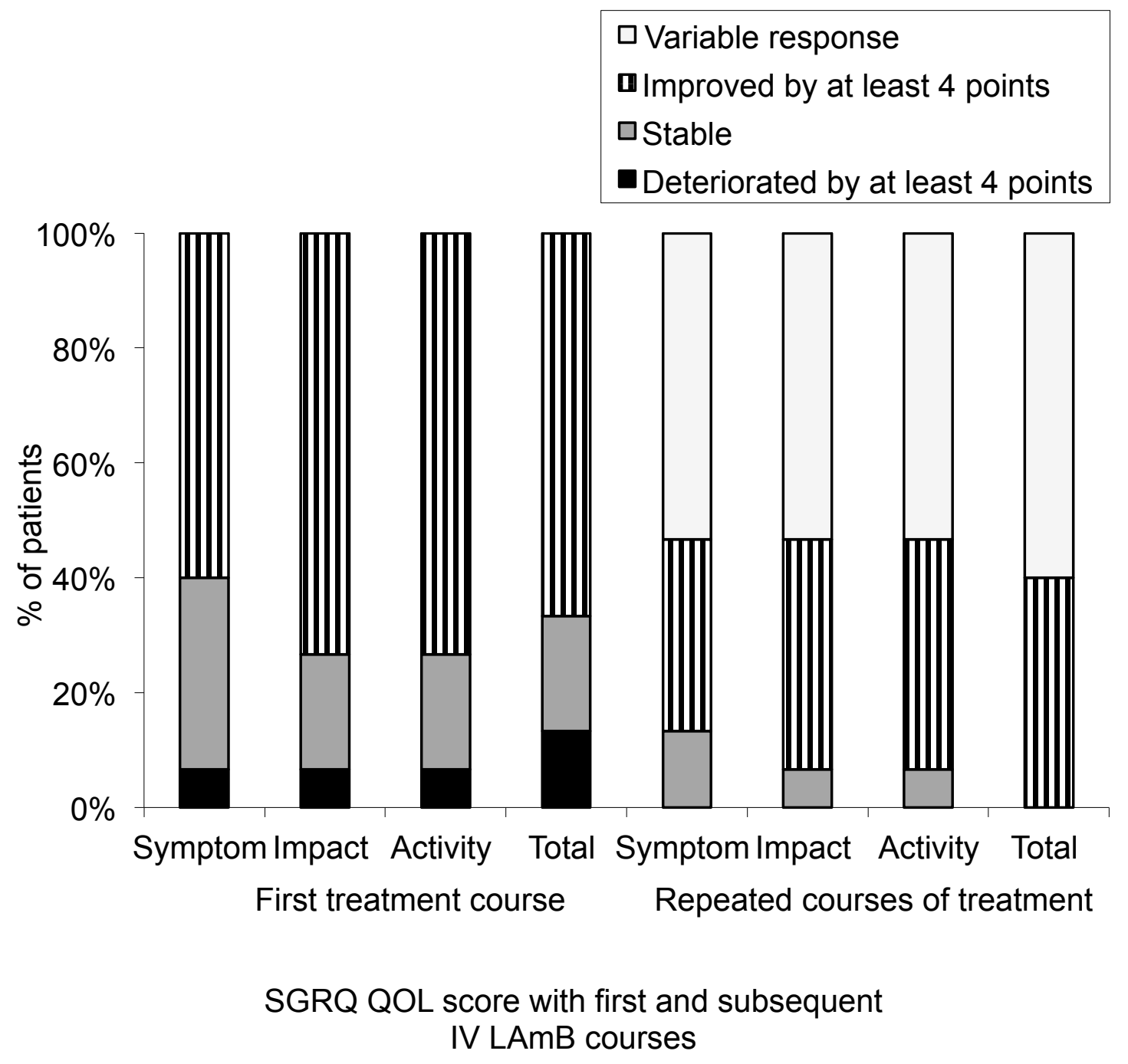


Figure 4A and 4B

The proportion of patients who developed a risk of an AKI or an AKI during their first course of IV LAmB treatment. Figure 4B refers to those 54 patients whose renal function was assessed beyond day 15 .

Figure 4A

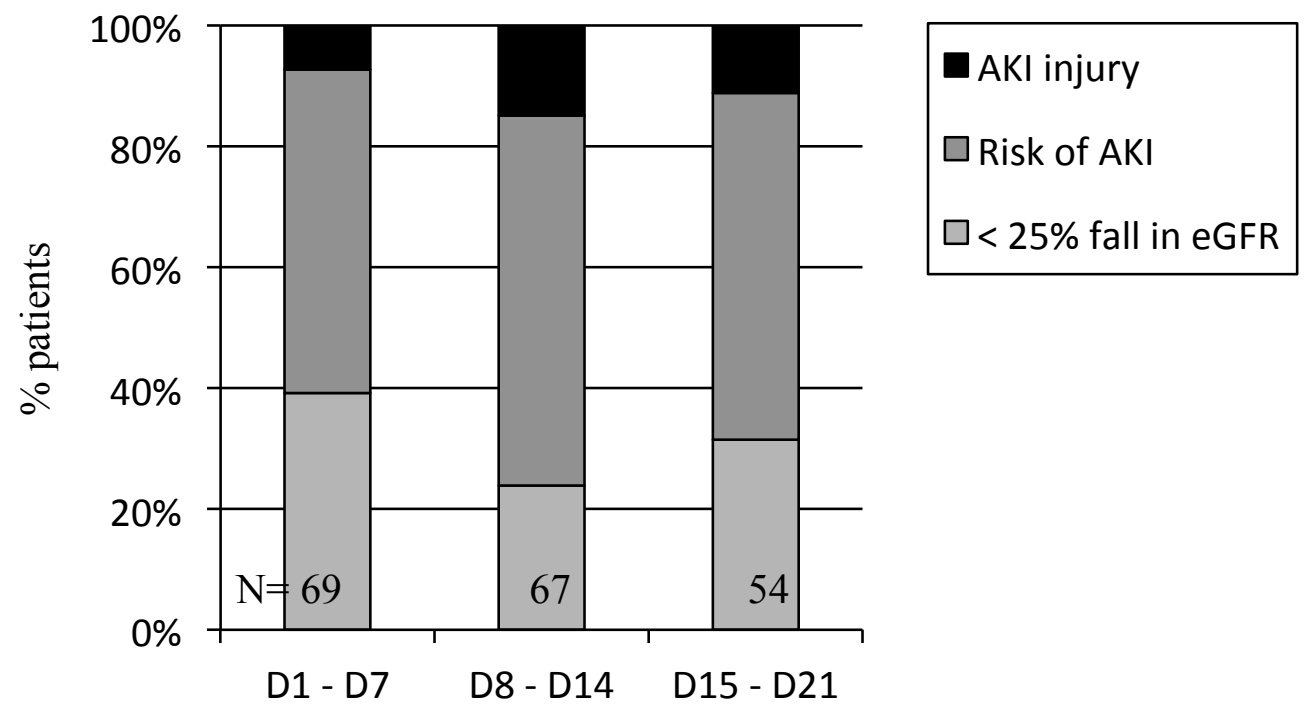

Days following commencement of IV LAmB therapy

$\underline{\text { Figure 4B }}$

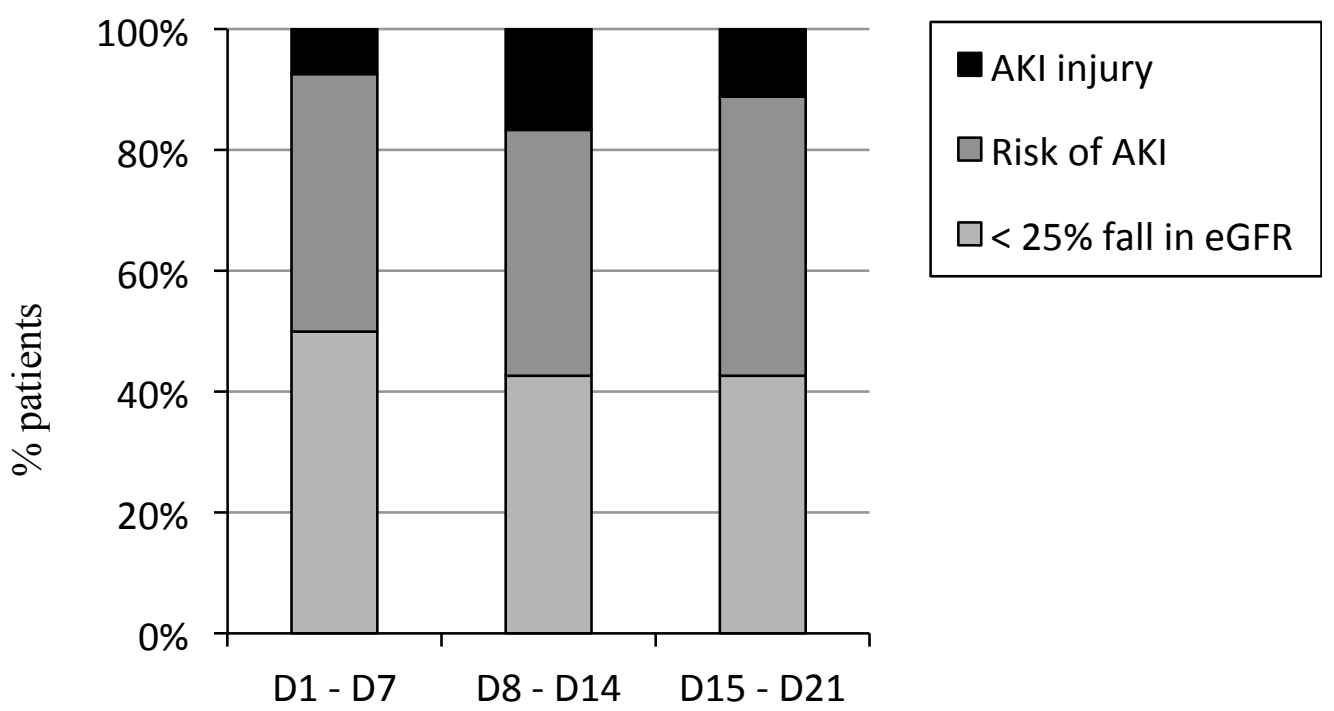

Days following commencement of IV LAmB therapy 
Figure 5A

Adjusted geometric mean eGFR observed in patients during and after their first course of LAmB therapy.

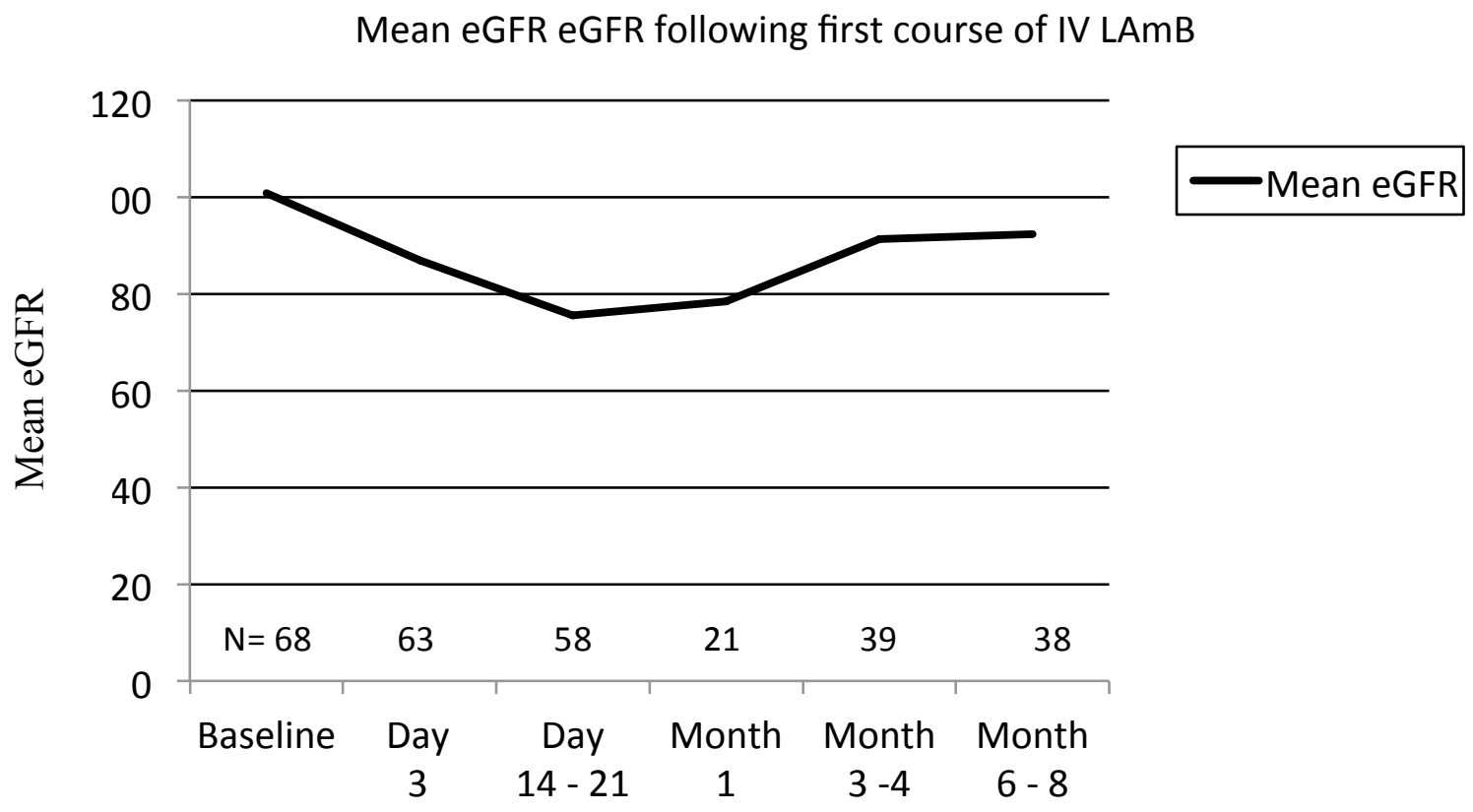

Figure 5B

Adjusted percentage of patients with an eGFR less than 90 during and post their first course of LAmB therapy.

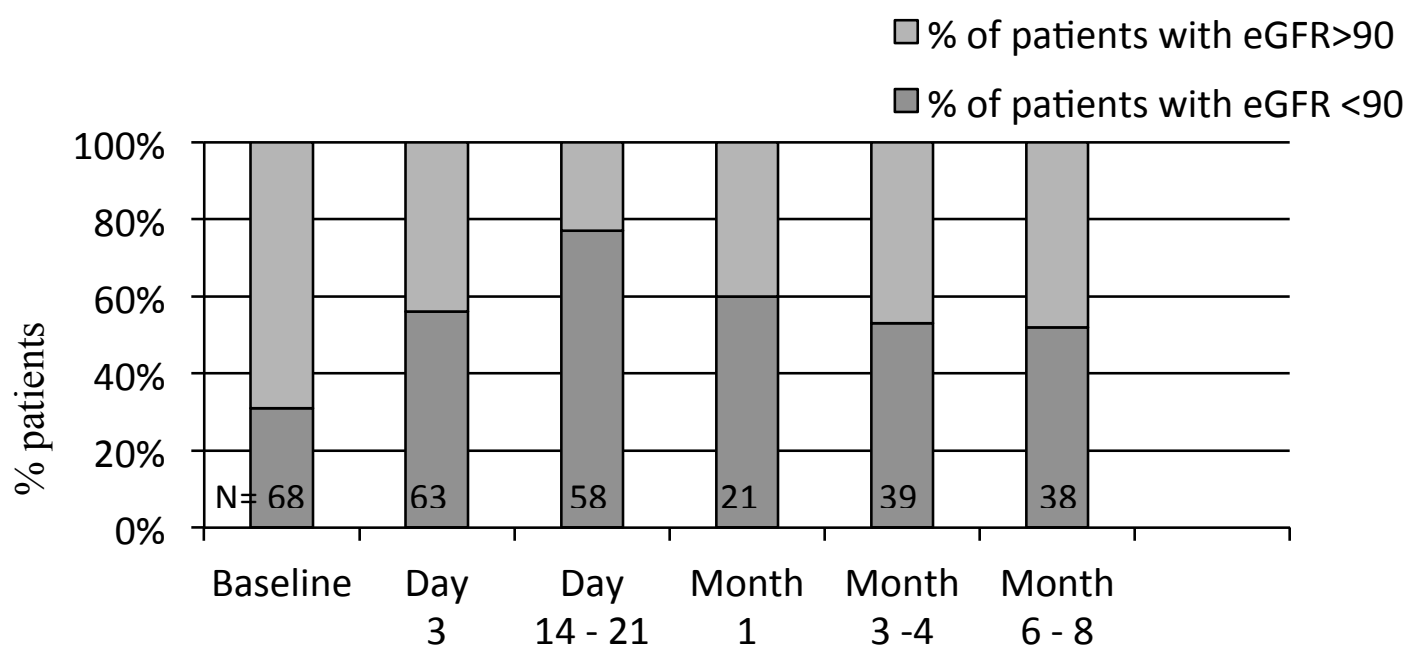

This data relates to the 68 patients who received at least 1 dose of LAmB therapy. Renal function post treatment was recorded for up to 8 months following therapy and the data at subsequent time-points was excluded from the analysis if patients had been commencing on a further short-course of LAmB therapy or intermittent long-term treatment. 
Figure 6A

Adjusted geometric mean eGFR observed in patients during and after their second course of LAmB therapy.

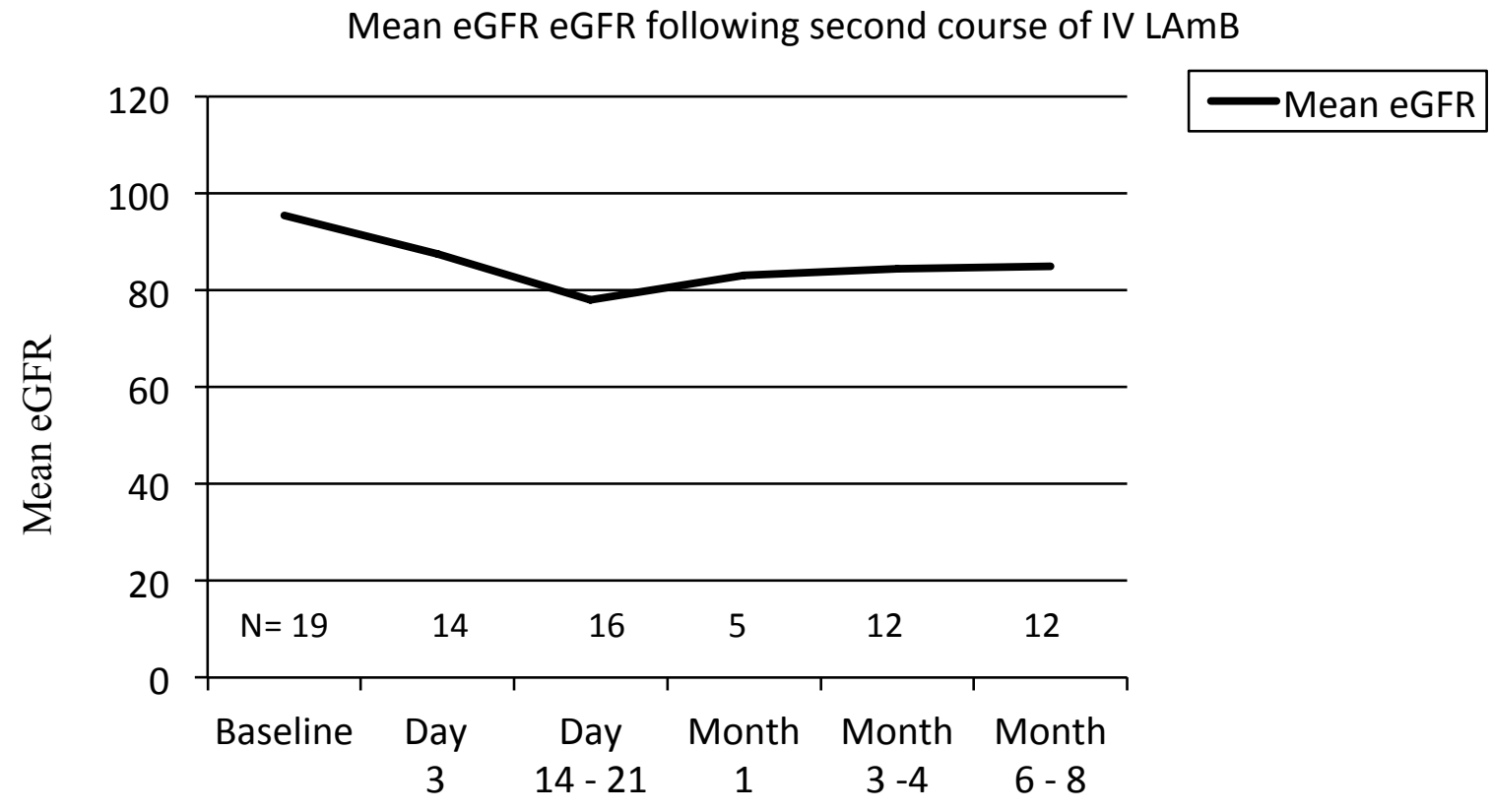

Figure 6B

Adjusted percentage of patients with an eGFR less than 90 during and post their second course of LAmB therapy.

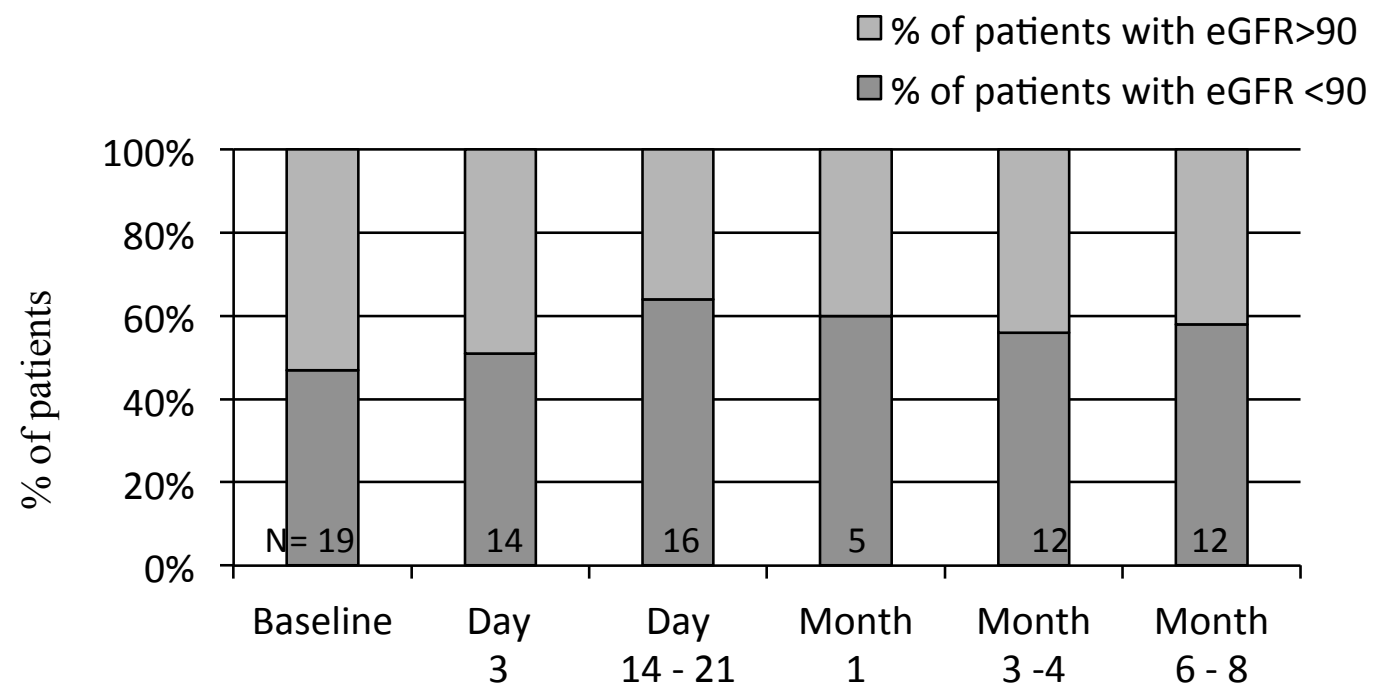




\section{Submission preparation:}

Figures - printed in black and white Print - black and white 